\title{
Low-Temperature Operation of Copper-Vapor Lasers by Using Vapor- Complex Reaction of Metallic Copper and Metal Halide
}

\author{
HIROSHI SAITO AND HIROSHI TANIGUCHI
}

\begin{abstract}
The first successful use of vapor-complex reactions for a laser is reported. Vapor-complex reactions between metallic copper and metal halides are found effective in reducing the operating temperature in copper-vapor lasers. By using a vapor-complex reaction of $\mathrm{Cu}+\mathrm{AlBr}_{3}$, a laser oscillation starts at a reservoir temperature of about $25^{\circ} \mathrm{C}$. The results obtained by the mass spectroscopic analysis support the presumption that the copper vapor is generated through a vapor-complex reaction process.
\end{abstract}

A METALLIC copper-vapor laser [1] possesses some excellent features. However, it has major disadvantage of high operating temperature. Substitution of a copper halide [2]-[4] and/or an organometallic copper [5][8] as the lasant permits operation at a lower temperature region and allows considerable simplification of the design of the laser tube. But the organometallic copper as the lasant has low efficiency and obstructs operation at a high pulse-repetition frequency [5]-[8].

As a prospect for new laser potential media, the use of the vapor-complex reactions for rare earths was carried out, and the characteristics of the fluorescence and optical gain were reported by Hessler et al. [9] and Jacobs and Krupke [10], [11] some time ago.

We have been thinking about the effective use of a volatile metal compound for metal-vapor generation through the reaction process at a low temperature. This paper describes the experimental results of the use of a vapor-complex reaction of metallic copper and volatile metal halides. This is the first report on the successful use of vapor-complex reactions for a laser.

An experimental setup similar to that in previous reports [1], [12] is used. A schematic diagram of the experiment is shown in Fig. 1. A laser tube is made of $1.25 \mathrm{~cm}$ ID $T$-shaped Pyrex with a branch tube (serves as the reservoir of a lasant) and with Brewster windows at both ends. The annular discharge electrodes made of brass are separated by $17-20 \mathrm{~cm}$, the total length of the laser tube is $35-40 \mathrm{~cm}$, and the inner diameter of the electrodes is about $0.6 \mathrm{~cm}$. The optical resonator of $55 \mathrm{~cm}$ spacing is formed by a flat dielectric-coated back reflector with high reflectivity and an output coupler of a flat dielectric-coated mirror with 43 percent transmittance at $510.6 \mathrm{~nm}$. Outside the portions of the reservoir and the discharge tube, nichrome wire heaters are separately wound and are surrounded by ceramic papers for thermal shielding. The

Manuscript received December 3, 1984; revised April 24, 1985. This work was supported in part by a Grant-in-Aid-for Scientific Research from the Ministry of Education, Science, and Culture of Japan.

The authors are with the Department of Electronic Engineering, Faculty of Engineering, Iwate University, Morioka-shi 020, Japan.

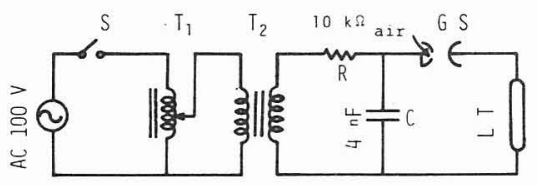

Fig. 1. Experimental setup used to excite the copper-vapor laser. $S$ : knife switch, $T_{1}: 0-130 \mathrm{~V}, 2 \mathrm{kVA}$ autotransformer, $T_{2}: 1: 60,3 \mathrm{kVA}$ single-phase transformer, $G S$ : air-blown type spark-gap switch, $L T$ : $T$-shaped laser tube, $C$ : energy storage capacitor.

reservoir temperature $\left(T_{r}\right)$ and the discharge-tube temperature $\left(T_{t}\right)$ at the central positions of each portion are measured independently by chromel-alumel thermocouples. The Viton "O" rings are used for gas sealing of the connections in the laser tube. Thus, quick assembly and disassembly of the laser tube become possible; the construction and handling of the device become simple and easy compared to that in other conventional devices.

Small pieces of both the metallic copper powders and the additional volatile metal halide are filled in the reservoir. The copper powder is placed close to the region of discharge and the metal halide is filled below the copper powders divided by quartz-glass wools in the reservoir tube. Metal-halide vapors generated by heating the reservoir at $T_{r}$ react on the metallic copper powder in the reservoir. Then the vapor complexes (presumably of the type $\mathrm{Cu}_{1} \mathrm{Al}_{\mathrm{m}} \mathrm{Cl}_{\mathrm{n}}$ ) are assumed to be generated.

A laser was driven by succéssive pulsed discharge of a storage capacitor $(C=4 \mathrm{nF})$ through a spark-gap switch of an air-blown type [12]. This was done in an aperiodic pulse train as a boosted-ac $(50 \mathrm{~Hz})$ high voltage of up to $5.4 \mathrm{kV}$ rms was switched directly by the spark-gap switch. The switch was operated at a repetition frequency of up to about $10 \mathrm{kHz}$ during each half cycle of the $50 \mathrm{~Hz}$ ac. Flowing He gas was used as a buffer gas. The discharge products were purged from the tube by a vacuum pump with the gas flow.

For three sets of metallic copper plus metal halide, the comparison of the laser-output characteristics (at the 510.6 $\mathrm{nm}$ line corresponding to neutral copper, $3 d^{10} 4 p\left({ }^{2} P_{3 / 2}^{0}\right)$ $3 d^{9} 4 s^{2}\left({ }^{2} D_{5 / 2}\right)$ transition) is shown in Fig. 2. By using $\mathrm{Cu}$ $+\mathrm{BiCl}_{3}, \mathrm{Cu}+\mathrm{AlCl}_{3}$, and $\mathrm{Cu}+\mathrm{AlBr}_{3}$, a laser oscillation is found to have started at a reservoir temperature of about 90,70 , and $25^{\circ} \mathrm{C}$, respectively. Fig. 2 also shows the laseroutput characteristics of $\mathrm{CuCl}$ alone for comparison to that of metallic copper plus metal halide in the operating temperature and the output-power intensity. The starting temperature of laser oscillation in the case of the $\mathrm{Cu}+\mathrm{AlBr}_{3}$ laser is about one order lower than in the case of $\mathrm{CuCl}$ alone, and about $1000^{\circ} \mathrm{C}$ lower than in the case of typical 


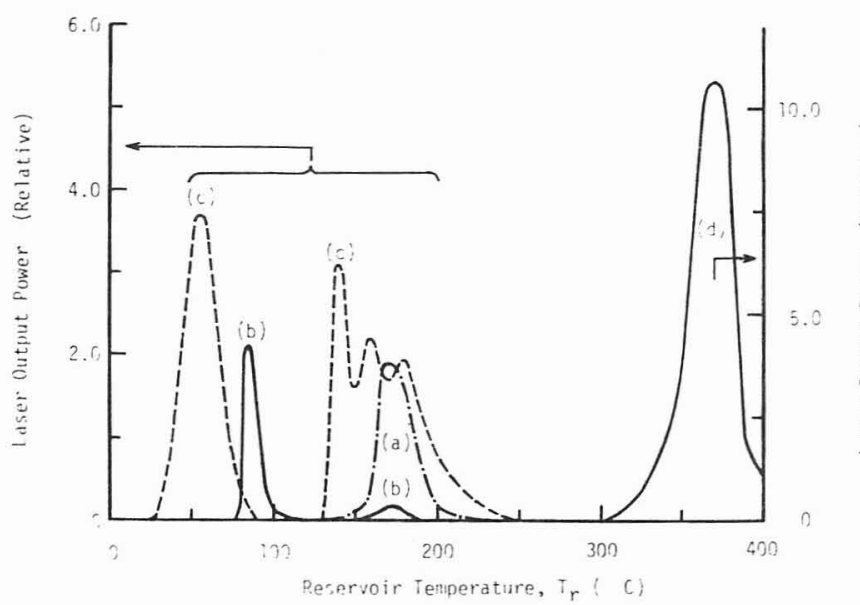

Fig. 2. Characteristics of the laser output intensity against the reservoir temperature $T_{r}$. (a) $\mathrm{Cu}+\mathrm{BiCl}_{3}$, internal pressure of the tube, $p=10$ torr (b) $\mathrm{Cu}+\mathrm{AlCl}_{3}, p=3$ torr. (c) $\mathrm{Cu}+\mathrm{AlBr}_{3}, p=10$ torr. (d) $\mathrm{CuCl}$ alone, $p=4$ torr. The tube temperature $T_{t}=350^{\circ} \mathrm{C}$, He buffer-gas flow rate $=30 \mathrm{~cm}^{3} / \mathrm{min}$, and applied voltage $V_{a}=5.4 \mathrm{kV}(\mathrm{rms})$ are fixed through all the measurements.

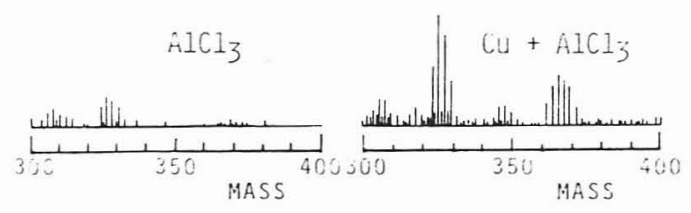

(a)

(b)

Fig. 3. Comparison of the results by mass spectroscopic analysis, (a) $\mathrm{AlCl}_{3}$, $T_{c}=140^{\circ} \mathrm{C}$, (b) $\mathrm{Cu}+\mathrm{AlCl}_{3}, T_{c}=110^{\circ} \mathrm{C}$

metallic copper-vapor lasers. For the $\mathrm{CuCl}$ alone, for example, it is shown in Fig. 2 that an adequate vapor pressure of the neutral copper atom for lasing is not obtained in any reservoir temperature under about $300^{\circ} \mathrm{C}$. Experiments were carried out by allowing the reservoir temperature to alter, while the tube temperature was fixed near the optimum temperature of laser performance. It was found experimentally that the He buffer gas flow rate of $30 \mathrm{~cm}^{3} /$ min was adequate for the laser operation.

The laser-pulse waveforms obtained in all the lasants typically exhibited a pulse duration (FWHM) of about 10 ns, which was measured with a calibrated HTV R1193U02 biplanar photo tube and an HP 1744A (100 MHz) storage oscilloscope system. The maximum peak power of a laser-output pulse measured with this system was about $0.8 \mathrm{~kW}$ in the $\mathrm{CuCl}$ lasers. As the driving voltage is low and the active length of the laser is relatively short, the laser was operated only near the peak voltage. The pulse repetition frequency of the laser was a few hundred hertz (a few pulses per each half cycle of the $50 \mathrm{~Hz} \mathrm{ac}$ ) for the $\mathrm{CuCl}$ fill in our best lasant. The laser was typically operated for about 60,60 , and 30 min with a single fill of 1 $\mathrm{g} \mathrm{Cu}$ with $1.5 \mathrm{~g} \mathrm{BiCl},-\mathrm{AlCl}_{3}$, and $\mathrm{lg} \mathrm{Cu}$ with $2.5 \mathrm{~g}-\mathrm{AlBr}_{3}$, respectively. The operating time of the laser was limited by the lifetime of volatile metal halide, and the powdery copper still remained to the last in the tube.

Mass spectroscopic analysis was carried out to check a process of metal-vapor generation in a low-temperature region. An analytical result measured with a Hitachi RMU-6M mass spectrometer is shown in Fig. 3. As a re- sult, in the case of a metallic copper alone, spectra of copper (and/or molecules including copper) never occurred in the temperature range of $T_{c}=100-200^{\circ} \mathrm{C}$, while in the case of $\mathrm{Cu}+\mathrm{AlCl}_{3}$, a series of strong spectra of the molecular type $\mathrm{CuAl}_{2} \mathrm{Cl}_{7}$, corresponding to the number of mass of about 360-370 (including $\mathrm{Cu}$ and $\mathrm{Cl}$ isotopes) was obtained at the cell temperature $\left(T_{c}\right)$ of $110-120^{\circ} \mathrm{C}$. The analytical results of the mass spectra support our presumption that the copper vapor is generated in the lower temperature region through a process of a vapor-complex reaction. We assume that the basic reaction originates in the vapor-complex reactions as reported by Dewing [13] and Øye et al. [14], and through the reaction process, higher vapor pressures occur at a low temperature. From the results of our work (see Fig. 2), we have reason to assume that the vapors of molecular type $\mathrm{CuAl}_{2} \mathrm{Cl}_{7}$ generate at a lower temperature by the use of volatilizable metal halide at a lower temperature.

To date in our work, we could realize a laser operation in a relatively high pulse-repetition frequency at a low operating temperature with a compact device. It is fundamentally different from the results of previous work [5], [8] in the areas of pulse-repetition frequency and efficiency.

The present system is not constructed to optimize the laser operation. Improved laser performance may be expected by modifications of the present system.

\section{REFERENCES}

[1] W. T. Walter, N. Solimene, M. Piltch, and G. Gould, "Efficient pulsed gas discharge lasers," IEEE J. Quantum Electron., vol. QE-2, pp. 474-479, 1966.

[2] C. S. Liu, E. W. Sucov, and L. A. Weaver, "Copper superradiant emission from pulsed discharge in copper iodide vapor, "Appl. Phys. Lett., vol. 23, pp. 92-93, 1973.

[3] C. J. Chen, N. M. Nerheim, and G. R. Russel, "Double-discharge copper vapor laser with copper chloride as a lasant," Appl. Phys. Lett. vol. 23, pp. 514-515, 1973.

[4] N. K. Vuchkov, D. N. Astadjov, and N. V. Sabotinov, "A copper vapor laser utilizing pure copper with an admixture of other chlorides," Opt. Commun., vol. 42, pp. 199-200, 1982.

[5] A. J. Andrews, C. E. Webb, R. C. Tobin, and R. G. Denning, "A copper vapour laser operating at room temperature," Opt. Commun., vol. 22, pp. 272-274, 1977.

[6] G. Chakrapani, T. A. P. Rao, A. A. N. Murty, and D. R. Rao, "Laser action in copper with copper acetate as a lasant," Appl. Phys. Lett., vol. 31, pp. 832-833, 1977.

[7] M. C. Gokay, M. Soltanoalkotabi, and L. A. Cross, "Copper acetylacetonate as a source in the $5106-\AA$ neutral copper laser," J. Appl. Phys., vol. 49, pp. 4357-4358, 1978.

[8] H. Saito, H. Taniguchi, and T. Ishikawa, "Metal $\beta$-diketone chelate vapor lasers (II)," Technol. Rep. Iwate Univ., vol. 18, pp. 23-33, 1984.

[9] J. 'P. Hessler, F. Wagner, Jr., C. W. Williams, and W. T. Carnall, "Fluorescence from the $\mathrm{TbCl}_{3}-\mathrm{AlCl}_{3}$ vapor complex system: A potentia! new gas-phase laser," J. Appl. Phys., vol. 48, pp. 3260-3262, 1970.

[10] R. R. Jacobs and W. F. Krupke, "Optical gain at $1.06 \mu \mathrm{m}$ in the neodymium chloride-aluminum chloride vapor complex," Appl. Phys. Lett., vol. 32, pp. 31-33, 1978.

[11] _ - "Kinetics and fusion laser potential for the terbium chloridealuminum chloride vapor complex," Appl. Phys. Lett., vol. 35, pp. $126-128,1979$.

[12] H. Saito, K. Owashi, and T. Sakamoto, "A $510.6 \mathrm{~nm}$ copper vapor laser using $\mathrm{CuCl}_{2}$ with an air blow type gap switch"(in Japanese), Trans. Inst. Elec. Eng. Japan, vol. 103-C, p. 24, 1983.

[13] E. W. Dewing, "Gaseous complexes between dichlorides and trichlorides of aluminium and iron," Nature, vol. 214, p. 483, 1967.

[14] H. A. Øye and D. M. Gruen, "Neodymium chloride-aluminum chloride vapor complexes," .I. Amer. Chem. Soc., vol. 91, pp. 2229-2236, 1969. 